\title{
An EM Study of the Dorsal Nucleus of the Lateral Lemniscus: Inhibitory, Commissural, Synaptic Connections Between Ascending Auditory Pathways
}

\author{
Douglas L. Oliver and Amiram Shneiderman \\ Department of Anatomy, The University of Connecticut Health Center, Farmington, Connecticut 06032
}

The dorsal nucleus of the lateral lemniscus (DNLL) and its connections constitute one of the ascending auditory pathways to the inferior colliculus. One notable feature of this nucleus is the heavy commissural connections between DNLL on opposite sides of the midbrain. These commissural connections may have a significant impact on the ascending pathway. In this study, the fine structure of DNLL in the cat and its commissural connections were examined. Both anterograde and retrograde transport methods were used simultaneously at the EM level. Injections of ${ }^{3} \mathrm{H}$-leucine mixed with WGA-HRP were made in one DNLL. After axonal transport, EM autoradiographic methods were used to identify the anterogradely labeled axonal endings from the opposite DNLL. In the same location, retrogradely labeled neurons with crossed connections were identified with HRP histochemistry. Two types of axonal endings were found in DNLL, those with round synaptic vesicles forming asymmetrical synaptic junctions and those with pleomorphic vesicles and symmetrical synapses. Both types were equally common. However, only endings with pleomorphic vesicles were labeled after injections in the contralateral DNLL. The labeled endings from the opposite DNLL appeared to represent a homogeneous population, even though a number of variations in the 2 types of endings were found. Labeled endings were presynaptic to all parts of neurons in DNLL, but a large proportion of the synapses were on cell bodies and large dendrites. Two patterns of nuclear morphology and distribution of rough endoplasmic reticulum were identified and may represent different cell types. Examples of both cell types were observed to project to the contralateral side and received labeled synaptic endings.

The major finding of this study is that the crossed connections between DNLL exhibit the morphology associated with inhibitory function. Since neurons in DNLL are thought to use GABA as a neurotransmitter, the crossed connections could provide inhibitory inputs to DNLL on each side. Since some neurons receive numerous axosomatic inputs from the contralateral DNLL and also project to the opposite side, they may participate in direct reciprocal, inhibitory connec-

Received May 17, 1988; revised July 28, 1988; accepted Aug. 2, 1988.

This study could not have been completed without the help of Mrs. G. Beckius. Helpful comments on the manuscript were provided by Drs. M. Huerta, S. Kuwada, D. K. Morest, E.-M. Ostapoff, and C. Trahiotis. This rescarch was supported by NINCDS Grant R01-NS18391.

Correspondence should be addressed to Dr. Douglas L. Oliver at the above address.

Copyright (c) 1989 Society for Neuroscience $0270-6474 / 89 / 030967-16 \$ 02.00 / 0$ tions between the nuclei. Crossed inhibitory connections in the DNLL pathway may be important in regulating the flow of ascending auditory information.

The dorsal nucleus of the lateral lemniscus (DNLL) holds a unique position in the auditory system. Astride the fibers of the lateral lemniscus, DNLL receives most of the same projections that ascend to the inferior colliculus (Glendenning et al., 1981; Shneiderman et al., 1988); and DNLL also projects bilaterally to the inferior colliculus. Thus, the combined inputs and outputs of DNLL form a multisynaptic pathway, parallel to the other ascending pathways to the inferior colliculus (Goldberg and Moore, 1967; van Noort, 1969; Roth et al., 1978; Adams, 1979; Brunso-Bechtold et al., 1981; Kudo, 1981; Tanaka et al., 1985). By comparison, projections from the cochlear nucleus travel to the inferior colliculus by the direct pathways, while the indirect pathways pass through the superior olive (Oliver, 1987; Shneiderman et al., 1988). Since recent immunocytochemical data in the cat suggest that most, if not all, neurons in DNLL may contain GABA (Adams and Mugnaini, 1984), the DNLL pathway may differ from the other ascending pathways. The DNLL may provide an inhibitory input to the inferior colliculus.

Another important feature of the multisynaptic DNLL pathway is the direct, commissural connection between the DNLL on each side via the commissure of Probst (e.g., Probst, 1902; Shneiderman et al., 1988). These lateral connections are the first crossings in the auditory system above the level of the cochlear nuclei and superior olivary complex. Despite the pivotal and unique position of DNLL in the parallel ascending pathways, the synaptic organization and function of DNLL are not well understood. One hypothesis is that individual cells project to the opposite DNLL and also receive inhibitory inputs from the opposite side; thus, a reciprocal connection is created. This hypothesis requires testing at the EM level.

The present study provides the first observations of the DNLL and its commissural connections at the EM level. Through the use of axonal transport of ${ }^{3} \mathrm{H}$-leucine and EM autoradiography, the axonal endings from the opposite DNLL and their postsynaptic targets are identified. In the same material, these labeled commissural endings are compared with unlabeled axonal endings from the ascending pathways. These results demonstrate that the crossed connections between DNLL on the 2 sides have the synaptic morphology usually associated with inhibitory function and may participate in an inhibitory reciprocal relationship between the nuclei.

Preliminary reports of this material were presented in abstract form (Oliver et al., 1987a, b; Shneiderman and Oliver, 1988). 


\section{Materials and Methods}

Materials and methods were the same as those used in a previous study (Shneidcrman ct al., 1988). Five cats were deeply ancsthetized with $\mathrm{Na}$ pentobarbital $(35 \mathrm{mg} / \mathrm{kg})$ or a mixture of ketamine $\mathrm{HCl}(33 \mathrm{mg} / \mathrm{kg})$ and acepromazine maleate $(1.1 \mathrm{mg} / \mathrm{kg})$. The surface of the tegmentum overlying DNLL was surgically exposed. Saline solutions of ${ }^{3} \mathrm{H}$-leucine $\left({ }^{3} \mathrm{H}\right.$ Leu; 50-200 $\mathrm{mCi} / \mathrm{ml}$; specific activity, $58 \mathrm{Ci} / \mathrm{mmol}$; ICN Radiochemicals \#20036) mixed with either 10\% HRP (Boehringer Mannheim) or $0.7-1.2 \%$ wheat germ agglutinin conjugated with HRP (WGA-HRP; Sigma) were injected through an air-pressure system (Picospritzer, General Valve) and a glass micropipette (10-50 $\mu \mathrm{m}$ tip diameter). During the postoperative period, subjects were monitored for signs of distress, dehydration, and infection, and none were observed. Two days after injections, the animals were perfused while under deep pentobarbital anesthesia, and the tissue was prepared for light microscopy (LM) and EM (Oliver, 1984a, 1987).

Histological methods. Autoradiographic methods were used to reveal the anterograde transport of ${ }^{3} \mathrm{H}-\mathrm{Leu}$ at both the LM and EM levels. Sectioning and subsequent processing of tissue for EM took place in phosphate buffer $(0.12 \mathrm{M}, \mathrm{pH} 7.2-7.4)$ that contained $6 \%$ sucrose. The tissue was serial-sectioned with a Vibratome so that sections for EM were $100 \mu \mathrm{m}$ thick and spaced $300 \mu \mathrm{m}$ apart. The intervening sections were either 30 or $40 \mu \mathrm{m}$ thick for LM autoradiography (Cowan et al., 1972; Edwards, 1972; Oliver, 1984a) or $50 \mu \mathrm{m}$ thick for HRP histochemistry methods that use DAB (Adams, 1981) or TMB reagents (Mesulam, 1978). Sections were counterstained with neutral red or cresyl violet. The $100-\mu \mathrm{m}$-thick sections were prepared for EM after the DAB reaction. Sections were rinsed in buffer, osmicated (huffered 1\%), blockstained in 2\% uranyl acetate, dehydrated, and embedded in resin (Epox 812, E. F. Fullam). The EM autoradiographs were prepared according to methods described previously (Kopriwa, 1973; Oliver, 1984a, 1987). These methods can detect the small amounts of radioactivity found in axonal endings after axonal transport of ${ }^{3} \mathrm{H}$-labeled amino acids (Salpeter el al., 1977; Oliver, 1985).

The areas of DNLL to be examined at the EM level were selected from the regions with heavy labeling in LM autoradiographs (Fig. 1, $A$, $\left.C^{\prime}, E\right)$. The $100-\mu$ m-thick section was trimmed for EM, while semithin, $1 \mu \mathrm{m}$ sections were collected and stained to confirm the alignment of the EM sample with the LM autoradiograph. The DNLL was easily identified using cytoarchitectonic criteria (Shneiderman et al., 1988) in both plastic sections and LM autoradiographs. The samples chosen for EM analysis were confined to DNLL.

Analysis. Analysis of the EM autoradiographic material took place after exposure times of 5-50 weeks. A JEOL 100CX or Philips 300 microscope was used. To establish the presence of statistically significant labeling, a $\chi^{2}$ analysis was performed to compare actual labeling to a random distribution (Blackett and Parry, 1973; Parry, 1976; Salpeter et al., 1978; Oliver, 1985, 1987). The hypothetical grain procedure was used to estimate the distribution of radioactive sources in the tissue (Oliver, 1985, Appendix). The DNLL was subdivided into mutually exclusive tissue compartments-axonal endings with round and pleomorphic synaptic vesicles were assigned to separate compartments. Tissue compartments heavily labeled by axonal transport displayed the highest proportion of grains per unit area. Other quantitative analyses included counts of every labeled ending in selected autoradiographic sections and ratios of labeled versus unlabeled endings.

\section{Results}

Injections of ${ }^{3} \mathrm{H}$-leucine and WGA-HRP were placed in DNLL on one side, after which the opposite DNLL was prepared for EM autoradiography. The injection sites (Fig. 1, $B, D, F$ ) include virtually all of DNLL. As in previous studies (e.g., Oliver and Hall, 1978), autoradiographic injections were defined as regions where neuronal somata are labeled more heavily than the surrounding neuropil. In these cases, the HRP injection sites were comparable to those defined with LM autoradiography (Shneiderman et al., 1988).

All autoradiographic label in DNLL (Fig. 1, $A, C, E$ ) is due to anterograde transport from the contralateral DNLL (Henkel and Shneiderman, 1988; Shneiderman et al., 1988). Each part of DNLL receives inputs from the opposite side, including the lateral subdivision where neurons from DNLL and the sagulum are intermixed. The nucleus sagulum (Fig. 1, SAG), subcollicular tegmentum (Fig. 1, SU), intermediate nucleus of the lateral lemniscus (Fig. 1, IL), and inferior colliculus (Fig. 1, IC) do not project to the contralateral DNLL. Thus, in the areas sampled for analysis at the EM level (Fig. 1, $A, C, E$ ), the only source of labeled axonal endings is the opposite DNLL.

\section{Morphology of axonal endings in DNLL}

Two main types of axonal endings can be identificd by the morphology of their synaptic vesicles and synaptic contacts (e.g., Figs. 2-6: R, PL; synaptic contacts, arrowheads). The first type are the axonal endings with round synaptic vesicles that make asymmetrical synaptic contacts (type 1: Gray, 1959). The second type are those endings with pleomorphic synaptic vesicles that make symmetrical synaptic contacts (type 2). Both types of endings are equally common (Table 1), but only the endings with pleomorphic vesicles are significantly labeled in EM autoradiographs (Table 2).

A number of varieties of these 2 types of endings also are found in DNLL. These could represent axonal endings from different cell types or simply variations of the 2 types of endings. For example, most endings have small-to-medium, evenly scattered, round synaptic vesicles (Figs. $2, A, B ; 3 B ; 4$; and $5, B$ : $\mathrm{R})$. Other endings have larger, round vesicles and asymmetric contacts with regularly spaced densities on the presynaptic side (Fig. 3, D: LR, double arrowheads). Another variety has more densely packed vesicles (Fig. 3, $C: \mathrm{R}$ ). Axonal endings that make symmetrical synapses have either pleomorphic vesicles or flattened vesicles. In the present material, most axonal endings with pleomorphic vesicles, including those labeled by axonal transport, display a mixture of rounded and flattened vesicle profiles (Figs. 3B, 4, silver grains). Other endings have many more consistently flattened vesicle profiles and are usually unlabeled (Figs. $3, B, C ; 4, A: \mathrm{F})$.

\section{Labeled endings with pleomorphic vesicles from the contralateral DNLL}

Test for nonrandom labeling. Even though the EM samples are from areas of heavy labeling, the grains observed in EM autoradiographs should reflect a nonrandom distribution. To demonstrate nonrandom labeling, a $\chi^{2}$ test is used to compare the distribution of silver grains in the EM autoradiographs to a random distribution of hypothetical grains. A total of 589 real grains were compared to 2154 hypothetical grains distributed at random in the same tissue. Each of the 3 cases illustrated in Figure 1 has a significantly nonrandom distribution of silver grains $(p<0.001)$.

Quantitative estimates of activity vs. area. Axonal endings with round and pleomorphic synaptic vesicles compose only 5 and $5.9 \%$ of the total tissue, respectively (Table 2 ). However, axonal endings with pleomorphic vesicles, despite their small relative area, contain $32 \%$ of the radioactivity after axonal transport of ${ }^{3} \mathrm{H}$-leucine from the contralateral DNLL. This is 5.4 times the radioactivity expected from random labeling. Endings with pleomorphic vesicles in individual samples from DNLL are labeled with $1.8-2.7$ grains $/ \mu \mathrm{m}^{2}$ (Fig. 6). In contrast, endings with round synaptic vesicles are labeled at or below background levels. Axonal endings are occasionally labeled by the anterograde transport of HRP or WGA-HRP. In the present DABtreated material, the HRP-reaction product is seen infrequently 

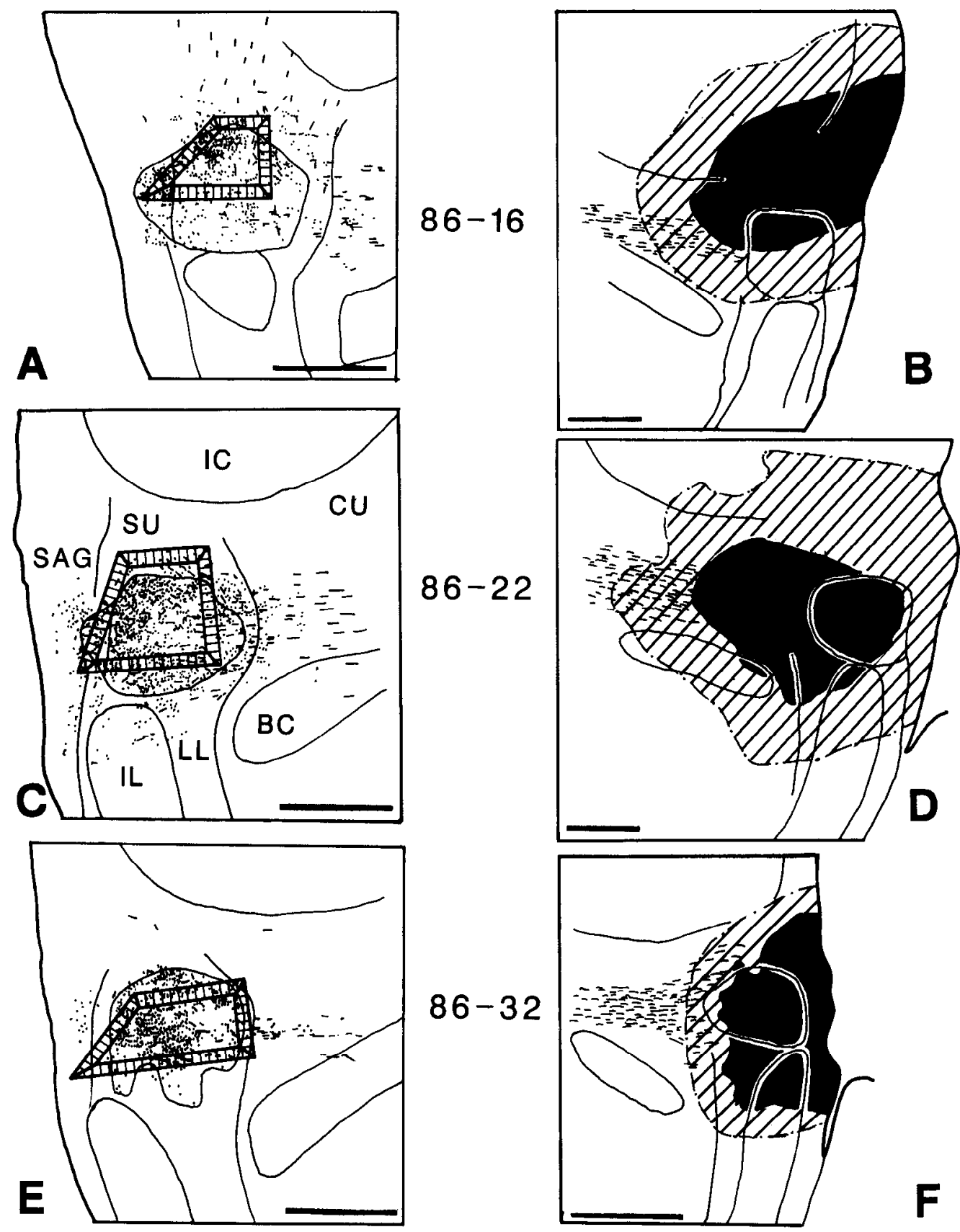

Figure 1. Location of EM samples $(A, C, E$, trapezoid) and injection sites $(B, D, F)$ in the dorsal nucleus of the lateral lemniscus. Center of injection site (black) and surrounding zone (crosshatch) are areas were the cell bodies are labeled more heavily than adjacent neuropil. Labeled fibers (lines) cross through the commissure and form terminal fields (dots) in the opposite DNLL. Transverse sections. Scale bars, $1 \mathrm{~mm}$.

in lysosomes or vesiculate organelles in axonal endings (e.g., Fig. $2 B$, open arrow).

Other tissue compartments are less heavily radiolabeled $(<1$ grain $/ \mu \mathrm{m}^{2}$ ) than axonal endings with pleomorphic vesicles. Nearly half of DNLL is occupied by glial elements, including compact myelin, while axons occupy about one-fourth. Postsynaptic elements (somata and dendrites), unmyelinated axons, and axonal endings make up the remainder. Most had a smaller proportion of the total radioactivity, and the radioactivity relative to the area was less than or equal to that expected by random labeling. Apart from the axonal endings with pleomorphic vesicles, most of the other radioactivity was in myelinated axons or glia (Table
2, Fig. 6). In one sample (86-16, $50 \mathrm{wk}$ ), the glia and compact myelin categories were separated to see if the labeling in those compartments could be distinguished. In that instance, the myelin category had a higher grain density (Fig. 6). The proportion of activity in the axoplasm or in the astrocytic compartment was very low.

Proportion of labeled vs. unlabeled endings. Although endings with pleomorphic vesicles were labeled quite heavily, not all endings of that type were labeled. When labeled endings (identified by one or more overlying silver grains) and unlabeled endings are counted in the micrographs used for the hypothetical grain procedure, the proportion of labeled versus unlabeled end- 

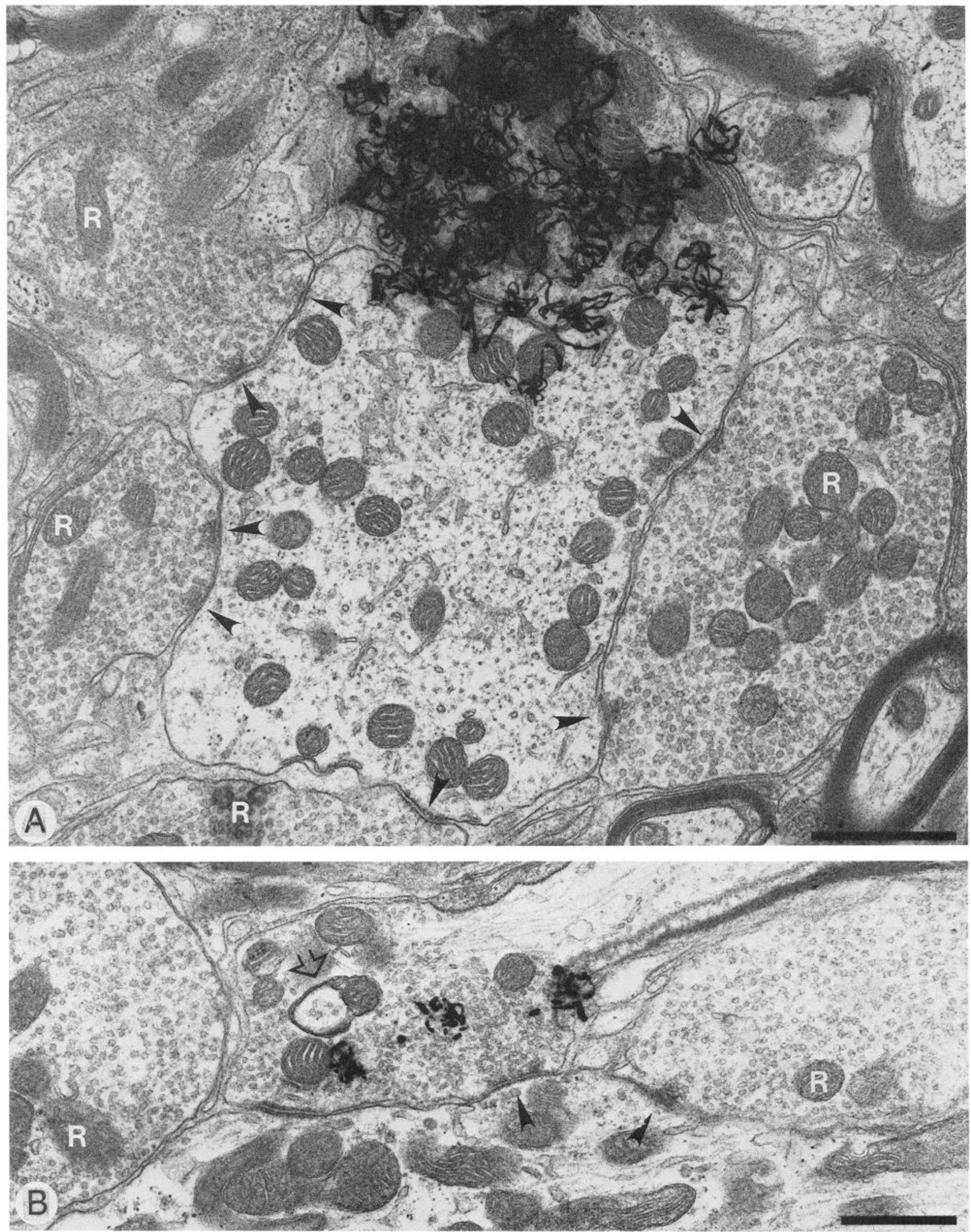

Figure 2. Axonal endings in contact with medium-to-large dendrites in case 86-16. $A$, Endings that contain round synaptic vesicles $(R)$ make multiple synaptic contacts (arrowheads) on a medium-sized dendrite cut in cross-section. A labeled ending, covered with silver grains after a long exposure, contains pleomorphic synaptic vesicles and appears to synapse on the same dendrite. $\times 27,000$. B, Both a labeled ending with pleomorphic vesicles and 2 unlabeled endings with round vesicles make synaptic contacts on a large dendrite cut longitudinally. A multivesicular organelle (open arrow) that may contain transported HRP also is present in the labeled ending. $\times 21,500$. Scale bars, $1 \mu \mathrm{m}$. 
Table 1. Distribution of types of axonal endings in DNLL and proportion of labeled versus unlabeled endings

\begin{tabular}{|c|c|c|c|c|c|}
\hline & \multicolumn{3}{|c|}{ Type of axonal ending ${ }^{a}$} & \multicolumn{2}{|c|}{$\begin{array}{l}\text { Proportion of class } \\
\text { labeled }^{b}\end{array}$} \\
\hline & $\mathrm{R}$ & PL & Total & $\mathrm{R}$ & PL \\
\hline $\begin{array}{l}86-16 \quad 9 \mathrm{wk} \\
n=169\end{array}$ & 49.0 & 51.0 & 100 & 6.0 & 21.5 \\
\hline $\begin{array}{l}86-1650 \mathrm{wk} \\
n=192\end{array}$ & 48.0 & 52.0 & 100 & 12.0 & 28.0 \\
\hline $\begin{array}{l}86-22 \\
n=348\end{array}$ & 54.0 & 46.0 & 100 & 5.0 & 31.0 \\
\hline $\begin{array}{l}86-32 \\
n=214\end{array}$ & 42.5 & 57.0 & 100 & 4.0 & 22.0 \\
\hline $\begin{array}{l}\text { Total } \\
\text { (SE) } n=4\end{array}$ & $\begin{array}{l}48.5 \% \\
(2.25)\end{array}$ & $\begin{array}{l}51.5 \% \\
(2.25)\end{array}$ & & $\begin{array}{l}6.75 \% \\
(1.80)\end{array}$ & $\begin{array}{l}25.6 \% \\
(2.32)\end{array}$ \\
\hline
\end{tabular}

Axonal endings from random samples used in the hypothetical grain analysis (Table 2) were classified based on their content of round $(\mathrm{R})$ or pleomorphic (PL) synaptic vesicles. In samples with significant labeling, the number of labeled axonal endings were counted. A labeled ending, in this analysis, had at least one silver grain over it. A total of 923 axonal endings were classified.

"Percentages of each type include both labeled and unlabeled endings.

Proportion of labcled cndings of cach type are calculated as a percentage from the total of labeled and unlabeled endings in that type.

ings can be determined. Of the 923 endings classified, approxinately hall contained pleomorphic synaptic vesicles. In this sample, $25.6 \%$ of the endings with pleomorphic vesicles were labeled after injections in the contralateral DNLL (Table 1). In contrast, less than $7 \%$ of the endings with round synaptic vesicles are associated with silver grains (Table 1). Many of these have only one silver grain on the edge of the ending (e.g., Figs. $4 B$, $5 B$ ) and probably represent labeling due to cross-scatter. Thus, these ratios and the results of the hypothetical grain procedure concur. Endings with pleomorphic vesicles are heavily labeled, and endings with round vesicles are labeled below background levels.

\section{Postsynaptic distribution of labeled endings}

To estimate the distribution of labeled endings from the contralateral DNLL, all heavily labeled endings ( 2 or more silver grains) in an EM autoradiograph were photographed and the postsynaptic structures were identified. In this analysis, a synaptic contact is visible on about $50 \%$ of the endings or is assumed to be present because the ending is juxtaposed to a postsynaptic structure without an intervening glial process. The results from nearly 400 labeled endings in both long- and short-exposure autoradiographs are presented in Table 3. As in the previous analysis, the majority of labeled endings contain pleomorphic synaptic vesicles $(96 \%)$. Although the largest proportion of labeled endings synapse on small dendrites $(<2 \mu \mathrm{m}$ in diameter), substantial numbers of labeled axonal endings are found on cell bodies and large dendrites. Presumably, cell bodies and proximal dendrites represent only a small proportion of the neuronal surface. Thus, these data suggest DNLL provides a heavy input to these structures.

Synaptic inputs on dendrites. Nearly a third of the labeled endings synapse on small dendrites (Table 3). When synapses are visible, the proportion is slightly lower $(27 \%)$. Some postsynaptic dendritic processes are quite small (Fig. 5, $C, D$ ). These may be dendritic spines or thin dendritic branchlets (e.g., Fig. $5, B, D)$ that contain few organelles. Small dendrites $(<2 \mu \mathrm{m})$ in diameter) may be distal dendrites of large neurons or more proximally located dendrites of smaller neurons.

Medium-sized dendrites ( $>2$ and $<3 \mu \mathrm{m}$ diameter) and large dendrites $(>3 \mu \mathrm{m})$ each represent about $16 \%$ of structures postsynaptic to labeled endings in this sample and about $21-23 \%$ of the endings with visible synaptic contacts. As shown in Figs. 2 and 3, medium and large dendrites are often surrounded by axonal endings. Many endings are partly separated from each other and from the surrounding neuropil by astrocytic processes. Only a fraction of the presynaptic elements surrounding large dendrites are labeled (e.g., Figs. $2 A$ and $3 A$, silver grains). Many of the larger dendrites may be proximal dendrites. Mediumsized dendrites could be a mixed population, including some proximal dendrites of small cells and the middle dendritic segments of other neurons.

Synapses on cell bodies. A most interesting result is the large number of labeled axonal endings that terminate on cell bodies. Nearly one-quarter of the endings with visible synaptic contacts terminated on cell bodies (Table 3 ), and it was not uncommon to find 2-4 labeled endings on a profile of a cell body in EM autoradiographs exposed for 24 weeks or more. For example, at least 7 labeled endings are visible on the cell body shown in Figure $7 A$ (arrowheads). Two of these are shown at higher magnification in Figure $8, A, B$. One of the axosomatic endings in Figure $7 B$ is shown at higher magnification in Figure $8 C$, while the ending on the cell with the round nucleus in Figure $7 C$ is

Table 2. Averaged results of hypothetical grain analysis in DNLL

\begin{tabular}{|c|c|c|c|c|c|c|c|}
\hline & \multirow{2}{*}{$\begin{array}{l}\text { Dendrites } \\
\text { somata } \\
n=4\end{array}$} & \multirow{2}{*}{$\begin{array}{l}\text { Axons } \\
n=4\end{array}$} & \multirow{2}{*}{$\begin{array}{l}\text { Glia } \\
\text { myel. } \\
n=4\end{array}$} & \multirow{2}{*}{$\begin{array}{l}\text { Unmyel. } \\
\text { axons } \\
n=3\end{array}$} & \multicolumn{2}{|c|}{ Axonal endings } & \multirow[b]{2}{*}{ Total } \\
\hline & & & & & $\begin{array}{l}\text { Round } \\
n=4\end{array}$ & $\begin{array}{l}\text { Pleo } \\
n=4\end{array}$ & \\
\hline Relative area & 16.1 & 22.1 & 49.9 & 3.1 & 5.0 & 5.9 & 102.1 \\
\hline (SE) & $(4.0)$ & (1.9) & (2.7) & $(2.0)$ & $(0.3)$ & $(0.9)$ & \\
\hline Relative activity & 6.2 & 13.7 & 45.7 & 0.3 & 2.4 & 31.8 & 100.1 \\
\hline (SE) & $(3.2)$ & (5.3) & (8.1) & $(0.2)$ & $(1.5)$ & (3.6) & \\
\hline $\begin{array}{l}\text { Activity/area } \\
\text { ratio }\end{array}$ & 0.4 & 0.6 & 0.9 & 0.1 & 0.5 & $5.4^{*}$ & \\
\hline
\end{tabular}

The proportion of radioactivity (relative activity) was compared with the relative area occupied by each tissue compartment Significant labeling $\left(^{*}\right)$ of a tissue compartment was indicated by a ratio of activity to area greater than 1 . Each tissue sample was significantly nonrandom $(p<0.001)$. In this analysis, 589 autoradiographic grains were compared with 2154 random grain/source combinations from the same samples as in Table 1. Myel., myelin; Pleo, pleomorphic vesicles; Round, round vesicles; SE, standard error; Unmyel., unmyelinated axon. 

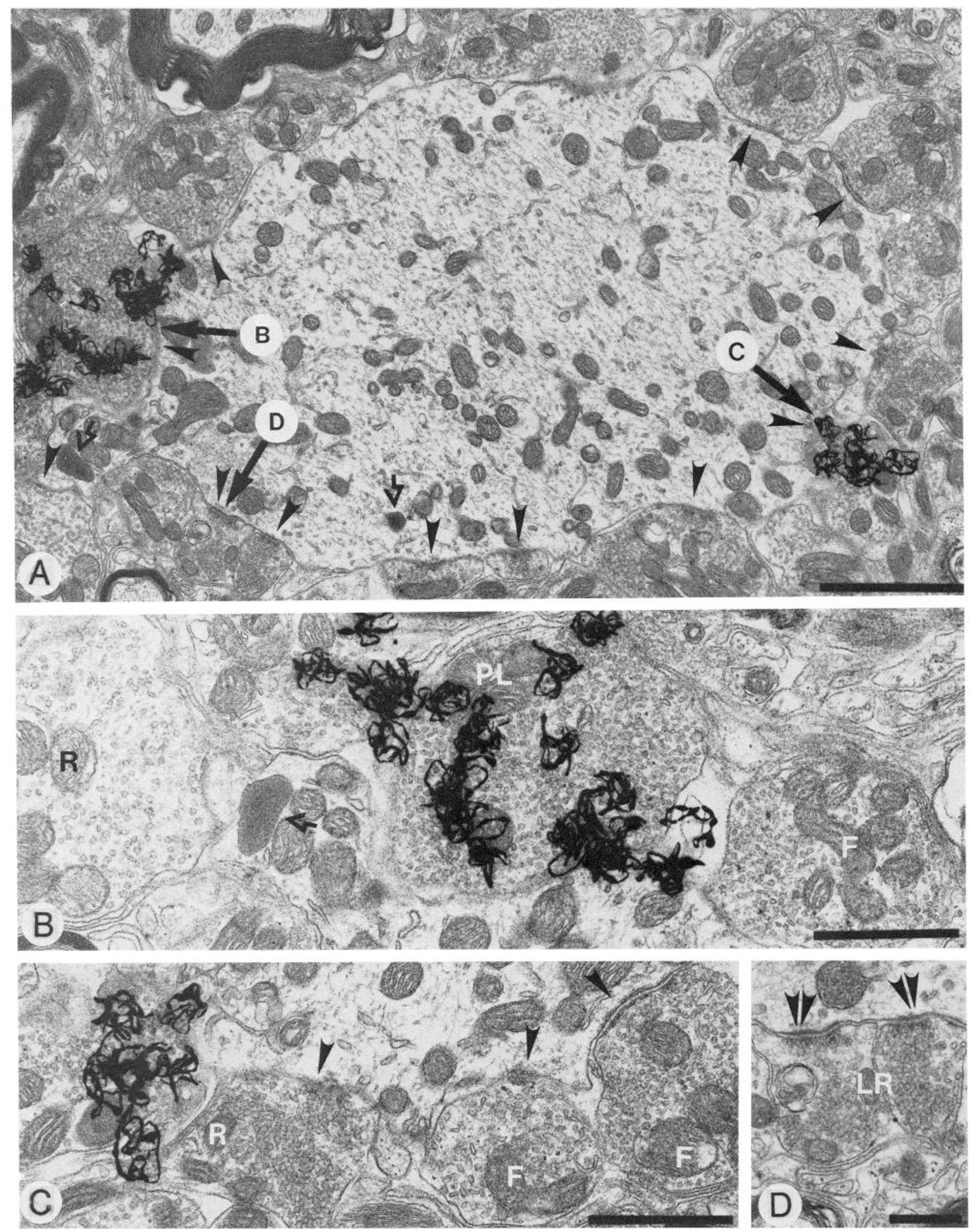

Figure 3. Axonal endings surrounding a large, possibly proximal dendrite cut in cross section in case 86-22. A, Lower-magnification micrograph shows that the surface of the dendrite is almost completely covered by axonal endings, many of which make synaptic contacts (arrowheads). Arrows indicate the location of endings enlarged in $B-D$. Several types of axonal endings are present. $B$ and $C$, Endings with medium-sized, round vesicles $(R)$; unlabeled endings with pleomorphic $(P L)$ or flat $(F)$ and labeled endings with pleomorphic vesicles (grains). $D$, Endings with larger, round vesicles $(L R)$ form asymmetric synaptic junctions (double arrowheads). Very dark lysosomes $(A, B$, open arrows) may indicate HRP that was transported from the contralateral DNLL. Magnification: $A, \times 13,500 ; B-D, \times 27,000$; Scale bar: $A, 2 \mu \mathrm{m} ; B$ and $C, 1 \mu \mathrm{m} ; D, 0.5 \mu \mathrm{m}$. 

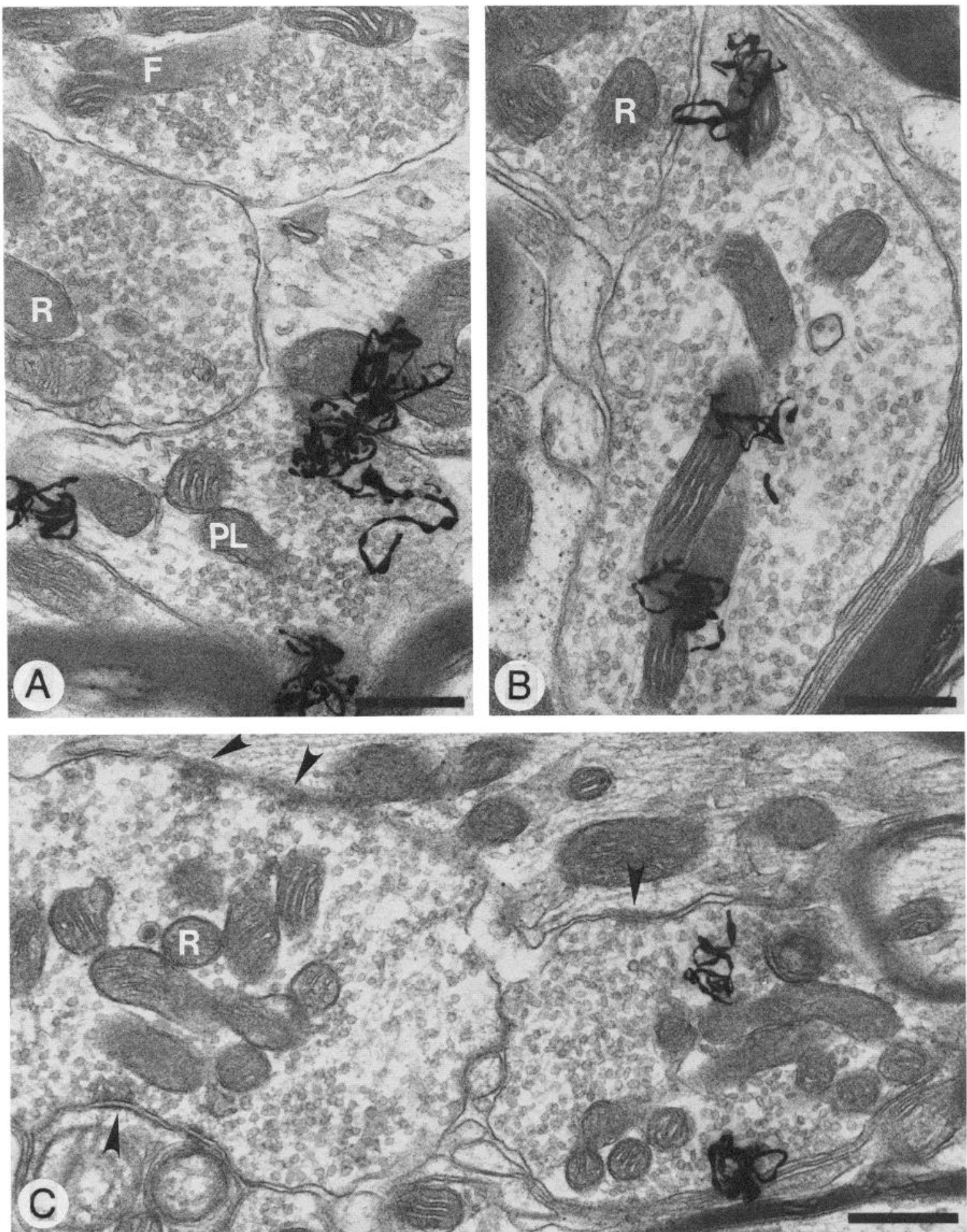

Figure 4. Labeled endings ( $A-C$, grains) and unlabeled endings from case 86-32. $A$, Some unlabeled endings $(F)$ have vesicles that are severely flattened. $B$, Most labeled endings have pleomorphic vesicles that are less flattened. $C$, Both labeled and unlabeled endings contact (arrowheads) a small dendrite. The ending with round vesicles also forms an asymmetric synaptic junction on a second process. $\times 35,000$. Scale bars, $0.5 \mu \mathrm{m}$.

shown in Figure $8 D$. Since the axosomatic endings are similar to axonal endings that terminate on dendrites, it is possible that both types of synapses arise from the same population of axons.

In the present material, some neurons have an irregularly shaped nucleus with perinuclear rough endoplasmic reticulum (Fig. 7, $A, B$, star). These are often neurons with fusiform-shaped cell bodies. Other cells have a rounded nucleus and lack the perinuclear reticulum (Fig. 7C). The relative proportion of these cell types is difficult to determine since cell bodies are infrequent in our sample and features of the cell body are sometimes obscured by the grid bars.

Labeled axosomatic endings are not always simple boutons terminaux (Fig. 8). Occasionally, they are elongated processes that make multiple synaptic contacts along the cell's surface 

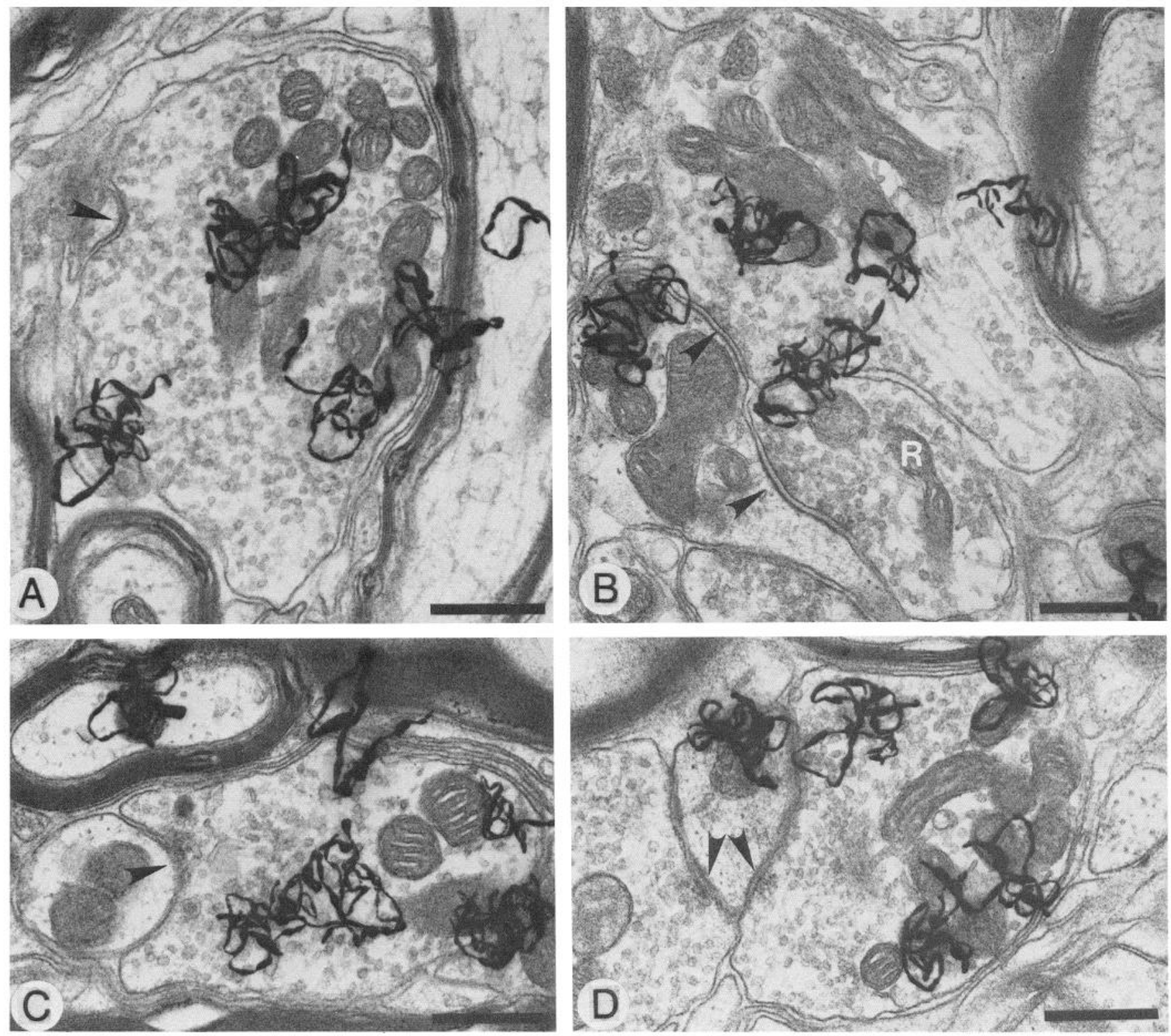

Figure 5. Labeled endings make synaptic contacts $(A-D$, arrowheads $)$ on small dendrites or appendages. These postsynaptic processes contain few organelles other than mitochondria and usually receive one synaptic contact. $B$ and $D$ show less common instances where 2 endings both synapse on the same dendritic process. In each case, one ending is labeled and the other is not. Case $86-32 . \times 35,000$. Scale bars, $0.5 \mu \mathrm{m}$.

(Fig. 9, $A-C$ ). These elongated processes have considerably more of their surface in contact with the postsynaptic cell body than smaller boutons. In the neuropil, multilobed axonal endings (Fig. $9 D$ ) are sometimes found. These could be elongated processes sectioned so that the axosomatic contacts are not seen, or they could be boutons en passant.

\section{Reciprocal connections of DNLL}

Although neurons in DNLL project to the opposite DNLL, the question remains whether the neurons with commissural connections also have synaptic inputs from the opposite side. In other words, is there evidence for direct, reciprocal synaptic connections between individual neurons in DNLL on both sides? Since HRP was injected along with the ${ }^{3} \mathrm{H}-\mathrm{Leu}$ in the present experiments, neurons in the opposite DNLL also are labeled by retrograde transport (Shneiderman et al., 1988). At the LM level, the heaviest HRP labeling and the heaviest autoradiographic labeling are colocalized in the same region of DNLL. In EM autoradiographs, direct evidence on this point is provided since both markers are readily visible. Some cell bodies and proximal dendrites in DNLL contain numerous lysosomal vesicles filled with HRP reaction product (Figs. 3, $A, B ; 7$, open arrows; 8, arrows). These same neurons receive numerous synaptic contacts from axonal endings labeled with the anterograde marker (Figs. 7, 8, silver grains). Thus, the double labeling suggests that some neurons with commissural connections receive a reciprocal input from the opposite DNLL.

\section{Discussion}

The major finding is that the commissural connections between the 2 DNLL exhibit the morphology often associated with inhibitory function. Axonal endings from the contralateral DNLL 
contain pleomorphic synaptic vesicles, make symmetrical synaptic contacts, and appear to represent a homogeneous population. About one-quarter of the endings with pleomorphic vesicles in random samples were identified as labeled endings from the contralateral DNLL. The labeling presents a striking pattern of heavy inputs to cell bodies and proximal dendrites. Nearly half of all labeled endings are on either cell bodies, large, or medium-sized dendrites. In contrast, the unlabeled axonal endings in DNLL are heterogeneous at the EM level and are likely to originate from a number of brain stem auditory nuclei. The present findings also suggest that a number of cell types are present in DNLL. Since neurons in DNLL may use GABA as a ncurotransmittcr (Adams and Mugnaini, 1984; Thompson ct al., 1985; Moore and Moore, 1987; Roberts and Ribak, 1987), they could provide inhibitory inputs to the opposite DNLL. Some neurons may have direct, reciprocal inhibitory connections with the opposite DNLL.

\section{Morphology of axonal endings in DNLL}

The present findings show that DNLL contains a variety of axonal endings with round and pleomorphic synaptic vesicles associated with asymmetrical and symmetrical synapses, respectively. These features also distinguish different types of endings in other parts of the CNS. For example, many of the endings described here are similar to endings classified by synaptic vesicle shape and size in the inferior colliculus (Oliver, 1984a, 1985, 1987), lateral superior olive (LSO: Cant, 1984), the cochlear nucleus (Lenn and Reese, 1966; Kopf-Maier, 1979; Cant, 1981; Tolbert and Morest, 1982; Smith and Rhode, 1985), and the medial geniculate body (Morest, 1975). Endings with round synaptic vesicles are usually linked to excitatory synapses, while endings with pleomorphic vesicles may use inhibitory transmitters (e.g., Uchizono, 1965; Lund and Westrum, 1966; Wallberg, 1966; Valdivia, 1971).

Axonal endings with pleomorphic synaptic vesicles are labeled in DNLL and arise from the contralateral side. Pleomorphic vesicles and symmetrical synapses have been found in axonal
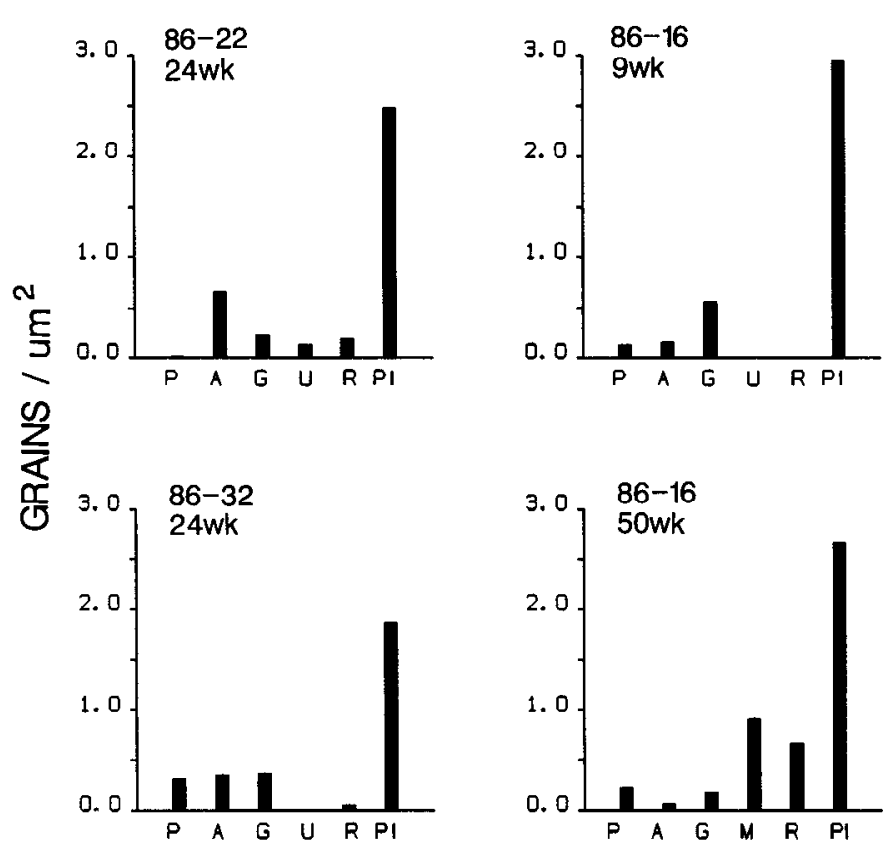

Figure 6. Grain-density histograms to show the relative distribution of radioactivity in the tissue compartments of DNLL. Axonal endings with pleomorphic synaptic vesicles $(P L)$ are most heavily labeled. $P$, postsynaptic structures (cell bodies and dendrites); $A$, myelinated axons (not including compact myelin); $G$, glia (all non-neuronal cells including compact myelin); $U$, unmyelinated axons (may also include very small dendrites); $M$, compact myelin; $R$, axonal endings with round synaptic vesicles.

endings that may use GABA as a neurotransmitter (e.g., McLaughlin et al., 1974; Hökfelt and Ljungdahl, 1975; Kelly et al., 1975; Ribak et al., 1977; Ribak, 1978; Vaughn et al., 1981; Wenthold et al., 1986). Our data show that about $25 \%$ of the endings with pleomorphic vesicles are labeled in DNLL. This may be a conservative estimate. Only low levels of radioactivity may be present in some endings. Alternatively, not all of the

Table 3. Distribution of labeled axonal endings on postsynaptic structures

\begin{tabular}{|c|c|c|c|c|c|c|}
\hline & & Dendrit & & & & \\
\hline & Somata & Large & Medium & Small & Unknown & \\
\hline 86-16 Pleo & 13.2 & 19.7 & 21.1 & 25.0 & 15.8 & $n=72$ \\
\hline 86-16 Round & - & - & 1.3 & 3.9 & - & $n=4$ \\
\hline 86-22 Pleo & 21.4 & 17.9 & 14.3 & 25.0 & 21.4 & $n=56$ \\
\hline 86-22 Round & - & - & - & - & - & $n=0$ \\
\hline 86-32 Pleo & 17.1 & 8.9 & 12.8 & 36.8 & 20.2 & $n=247$ \\
\hline 86-32 Round & - & 0.4 & 0.4 & 2.3 & 1.2 & $n=11$ \\
\hline Average Pleo & $17.2 \%$ & $15.5 \%$ & $16.1 \%$ & $28.9 \%$ & $19.1 \%$ & \\
\hline (SD) $n=3$ & $(4.1)$ & $(5.8)$ & $(4.4)$ & $(6.8)$ & $(2.9)$ & \\
\hline Average Round & - & $0.1 \%$ & $0.6 \%$ & $2.1 \%$ & $0.4 \%$ & \\
\hline (SD) $n=3$ & & $(0.2)$ & $(0.7)$ & $(2.0)$ & $(0.7)$ & \\
\hline Visible synapses $^{a}$ & 24.6 & 21.3 & 23.3 & 27.0 & 4.3 & $n=190$ \\
\hline
\end{tabular}

Every EM autoradiographically labeled ending in 7 complete thin sections was photographed, classified by vesicle morphology, and sorted by postsynaptic profile. In this analysis, labeled endings were defined as those associated with 2 or more silver grains. In case 86-16, 3 sections were used and were exposed 9 weeks. Case 86-22 represents 2 sections exposed 7 weeks. In case 86-32, 2 sections that had been exposed 24 weeks were mapped. A total of 390 axonal endings were classified. Large dendrites were $>3 \mu \mathrm{m}$ in cross-sectional diameter; medium-sized dendrites were $<3$ and $>2 \mu \mathrm{m}$; small dendrites were $<2 \mu \mathrm{m}$.

${ }^{a}$ This distribution is limited to the 190 endings in the sample with visible synaptic contacts. 

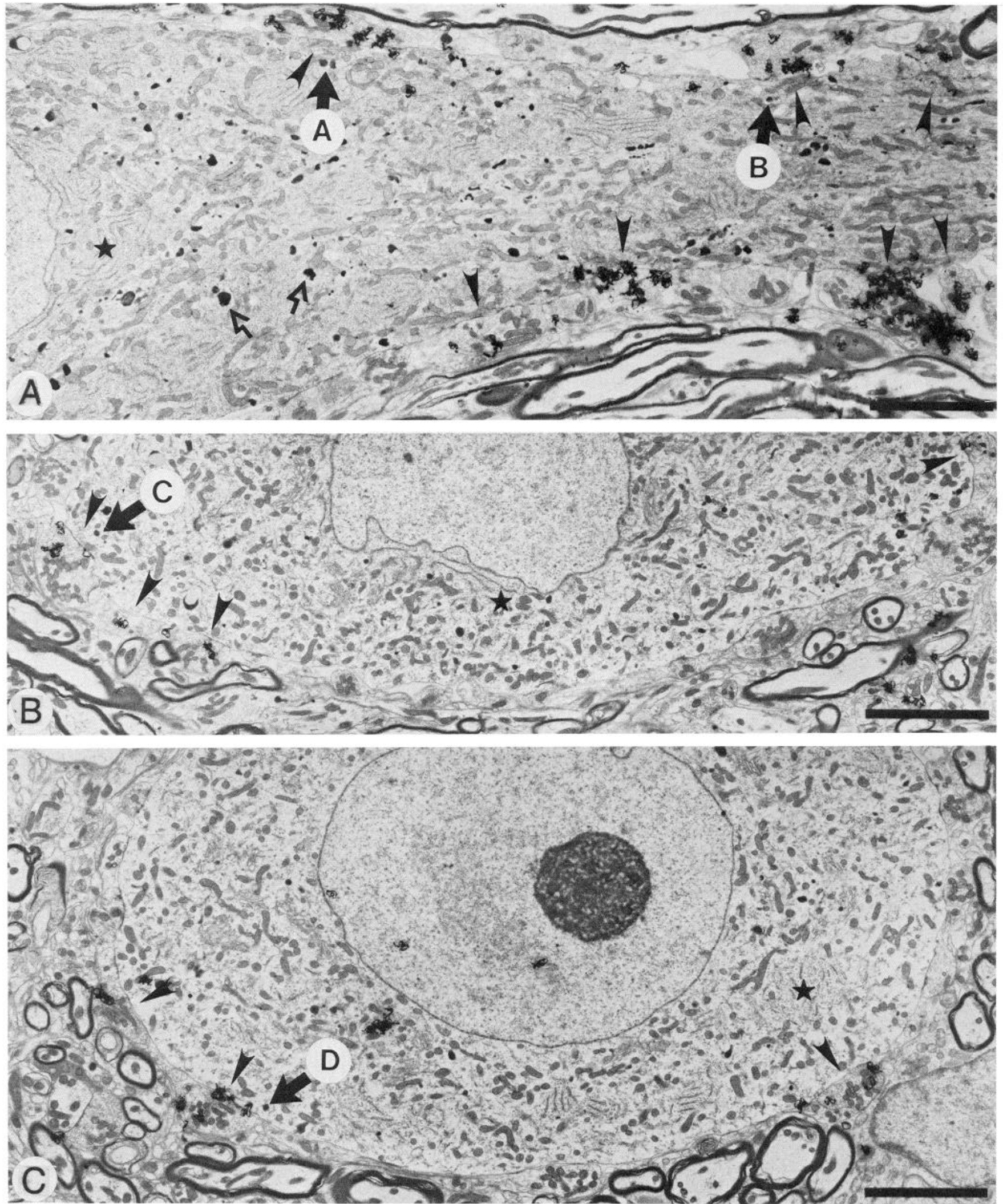

Figure 7. Cell types with labeled axosomatic synaptic contacts (arrowheads) from the contralateral DNLL are also retrogradely labeled with HRP. Cells in $A$ and $B$ have irregular nuclear shape and perinuclear rough endoplasmic reticulum (star). In $C$, the cell has a smooth nucleus and lacks perinuclear reticulum. Dark granules of HRP-reaction product in lysosomes are particularly obvious in $A$ (e.g., open arrows). Axonal endings indicated by arrows are shown in Figure 8 . Case 86-32. $\times 4400$. Scale bars, $5 \mu \mathrm{m}$. 

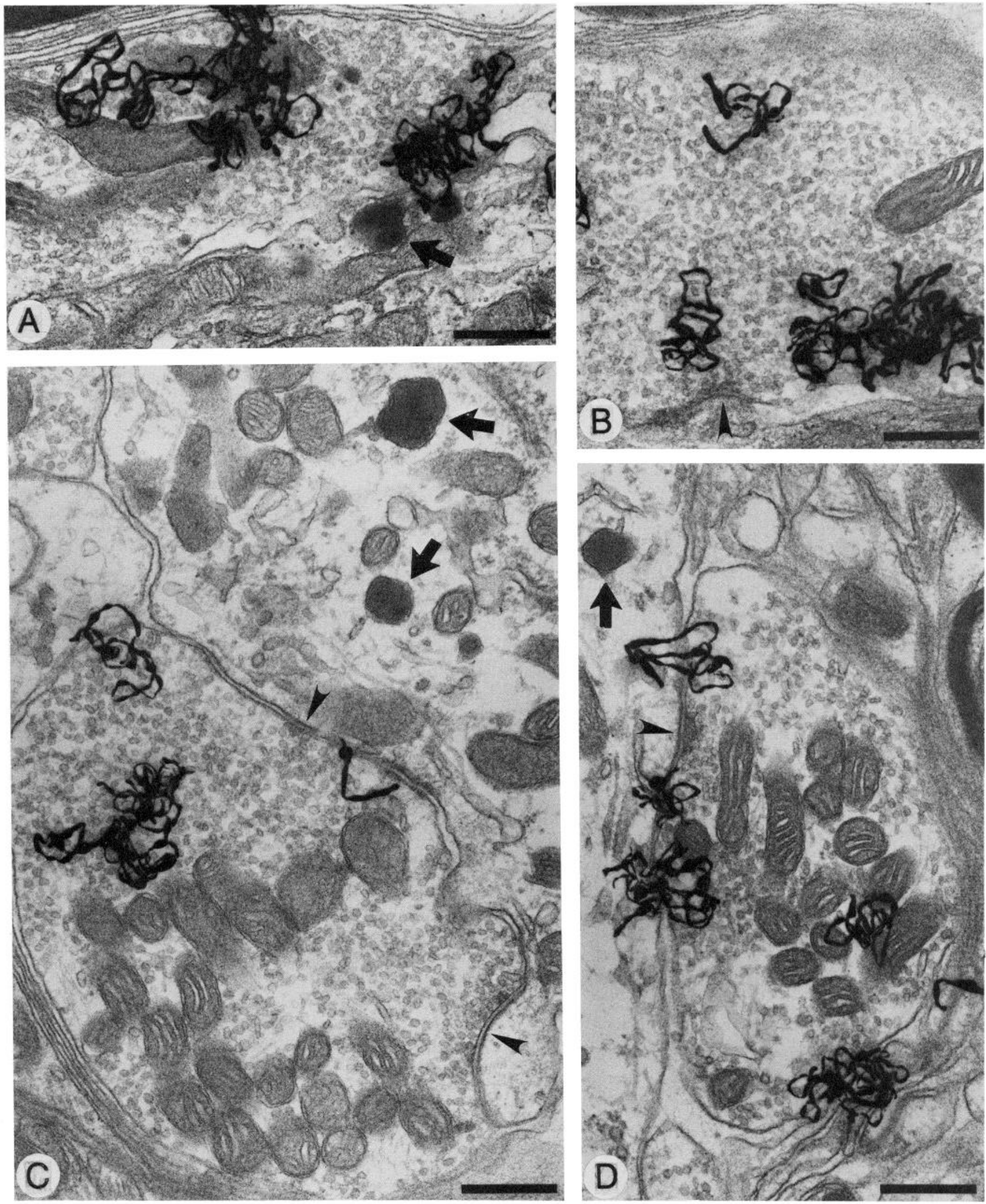

Figure 8. Higher magnification of radiolabeled axosomatic endings and HRP-labeled cell bodies. The endings typically make single, symmetric synaptic contacts (arrowheads) on the somata. Lysosomes indicated by arrows probably contain HRP reaction product. These neurons were retrogradely labeled with wheat germ-HRP that was mixed with the ${ }^{3} \mathrm{H}$-leucine and injected in the contralateral DNLL. Case $86-32$. $\times 35,000$. Scale bars, $0.5 \mu \mathrm{m}$. 

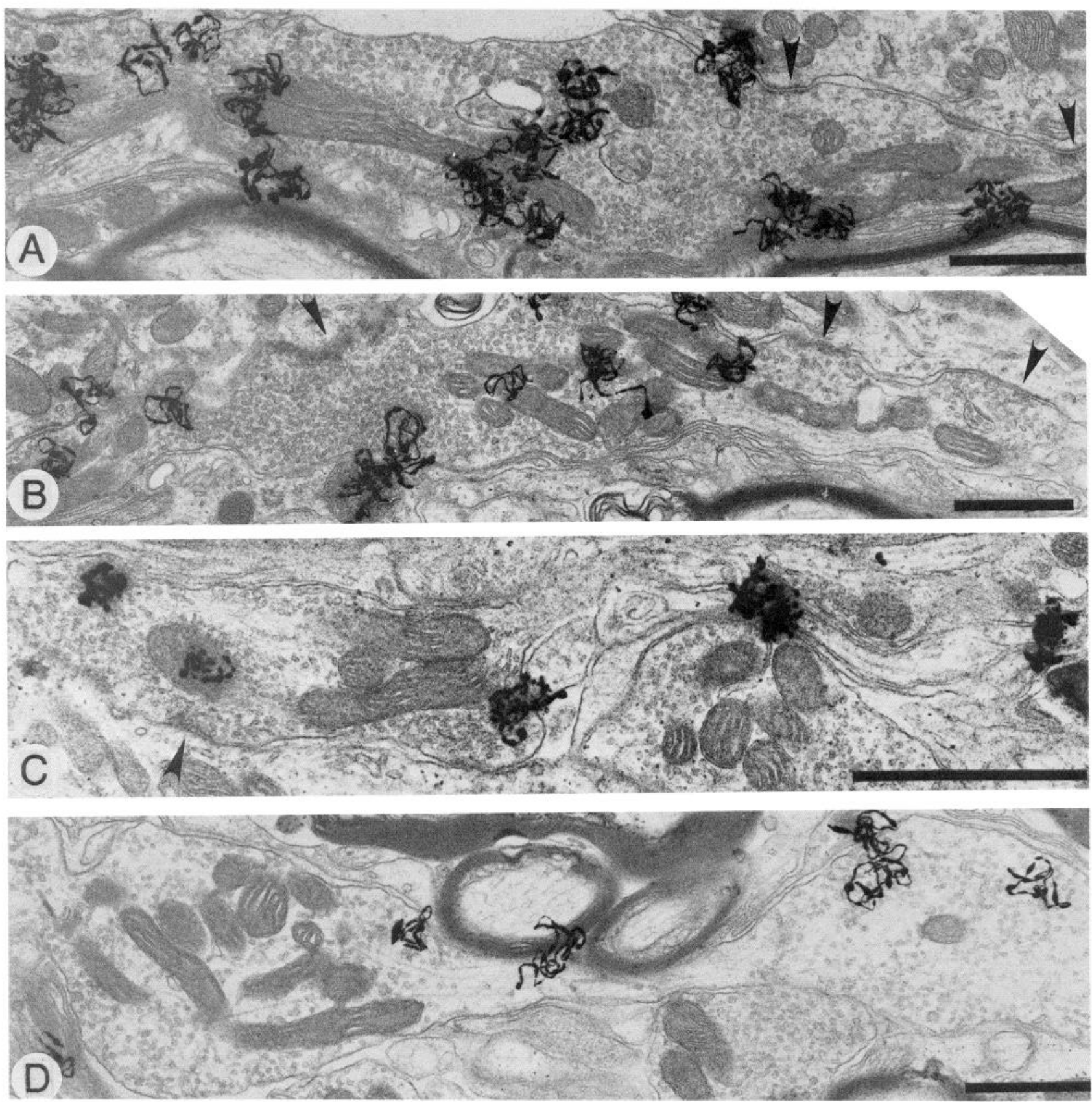

Figure 9. Large radiolabeled axonal endings that form axosomatic synapses $(A-C)$. These are elongated processes which make multiple synaptic contacts (arrowheads) along the cell body. $D$ shows a multilobed axonal ending seen in the neuropil. $A$ and $B$, Case $86-22 ; C$, case $86-16$; $D$, case 86-32. Magnification: $A, \times 20,800 ; B, \times 18,800 ; C, \times 36,600 ; D, \times 19,800$. Scale bars, $1 \mu \mathrm{m}$.

endings from the opposite DNLL may be labeled because the injections did not involve all parts of DNLL to the same extent. In addition, some radioactive endings may not have been counted due to cross-scatter. Silver grains are not always found over the source of the radioactivity in EM autoradiographs (Salpeter et al., 1977; Oliver, 1985).

There may be other sources of endings with pleomorphic vesicles besides the opposite DNLL. For example, some unlabeled endings with pleomorphic or flattened synaptic vesicles may come from LSO. The ipsilateral projection from LSO to the inferior colliculus is thought to include a substantial proportion of glycinergic fibers (Hutson et al., 1987; Saint Marie et al., 1987). Those same axons could project to the DNLL
(Shneiderman et al., 1988). Endings which may use glycine as a neurotransmitter may have pleomorphic or flattened synaptic vesicles (e.g., in LSO: Moore and Caspary, 1983; Cant, 1984). Other sources of type 2 endings in DNLL could be neurons in nearby midbrain structures or local axon collaterals from DNLL neurons. For instance, endings with pleomorphic vesicles could come from the adjacent sagulum or inferior colliculus (e.g., Thompson et al., 1985; Moore and Moore, 1987; Roberts and Ribak, 1987; Henkel and Shneiderman, 1988).

Axonal endings with round vesicles in DNLL are not labeled in the present study. Endings with round synaptic vesicles are associated with excitatory neurotransmitters (e.g., L-glutamate or L-aspartate in the auditory nerve: Kane, 1974; Wenthold and 
Gulley, 1977; Oliver et al., 1983; Potashner, 1983). Observations of endings with different sizes of synaptic vesicles, and other features, suggest that more than one variety of ending is present. Many of the brain-stem nuclei that provide inputs to DNLL (Glendenning et al., 1981; Shneiderman et al., 1988) also project to the inferior colliculus and could do so by means of collaterals (Iwahori, 1986). Endings with small, round vesicles have been identified in EM studies of the colliculus (Oliver, $1985,1987)$. Some of those endings are from the cochlear nucleus and may arise from stellate, fusiform (pyramidal), or giant cells (Osen, 1972; Adams, 1979; Cant, 1982). Since some of these sources project to DNLL, they could be a source of unlabeled endings with small, round vesicles. In contrast, endings with larger round vesicles may arise from other structures such as the superior olivary complex.

\section{Cell types in DNLL}

Previous anatomical and physiological investigations have shown DNLL to contain a heterogeneous population of neurons. In studies of Golgi-impregnated material, 11 cell types were defined in the cat (Kane and Barone, 1980), while 3 types were identified in the mouse (Iwahori, 1986). The present findings suggest that nuclear morphology and the distribution of rough endoplasmic reticulum distinguish different categories of cells. These features have been used to distinguish cell types in the cochlear nucleus and inferior colliculus (Cant and Morest, 1979; Cant, 1981; Oliver, 1984b). Electrophysiological studies of DNLL demonstrate a variety of responses to binaural stimuli (Aitkin et al., 1970; Brugge et al. 1970).

Cell types in DNLL may be related to their connections. Cells in DNLL appear to project to either the ipsilateral or contralateral inferior colliculus, but a few cells project bilaterally (Tanaka et al., 1985). This suggests that the commissural connection between the DNLL could represent inputs from at least 2 cell types, the neurons with contralateral projections and those with bilateral projections. In the present study, at least 2 cell types appear to participate in commissural connections, and examples of both cell types are shown to have direct, reciprocal connections with the opposite DNLL.

The number of functionally distinct cell types in DNLL could be related to the type of neurotransmitter present. In immunocytochemical studies, many cells in DNLL stain with GABA or GAD antibodies (Adams and Mugnaini, 1984; Thompson et al., 1985; Moore and Moore, 1987; Roberts and Ribak, 1987). Although most cells in DNLL of the cat are GABA-positive, other GABA-negative cells are found. No cells in DNLL are immunoreactive with glycine antibodies (Saint Marie, personal communication). Presumably, the labeled endings in this study represent the crossed projections of the GABAergic neurons in the DNLL.

\section{Commissural inhibitory inputs between opposite $D N L L$}

The crossed projections may provide significant inhibitory inputs to the opposite DNLL. Data at the LM level are consistent with the concept of tightly coupled reciprocal connections. After injections of HRP mixed with ${ }^{3} \mathrm{H}$-Leu into $\mathrm{DNLL}$, the region on the contralateral side with the heaviest retrograde labeling also had the heaviest anterograde label (Shneiderman ct al., 1988). At the EM level, some cells with projections to the contralateral side are double labeled. Thus, many cells that project to the contralateral DNLL may be involved in reciprocal con- nections. Other cells may not be involved in reciprocal connections but may receive an inhibitory commissural input.

Data from Golgi-impregnated material in DNLL (Iwahori, 1986) show that axons from the commissure of Probst contribute to pericellular baskets around the soma and proximal dendrites. At the EM level, the present results indicate that many of the axonal endings in the pericellular baskets make symmetrical synapses. Many of the labeled endings terminate on cell bodies or large dendrites. These locations are the most effective sites for synaptic inputs on a neuron. If the crossed DNLL pathway uses GABA and is inhibitory, the excitation of neurons in DNLL on one side may produce a dramatic reduction in the firing of neurons on the contralateral side.

\section{DNLL pathway vs. other ascending auditory pathways}

The auditory system of the brain stem consists of parallel, ascending pathways to the inferior colliculus, where most pathways synapse (see Oliver, 1987; Shneiderman et al., 1988, for discussion). The multisynaptic, DNLL pathway complements the direct pathway from the cochlear nucleus and indirect pathway via the superior olivary complex. Direct pathways travel uninterrupted from the dorsal and ventral cochlear nuclei to the inferior colliculus (e.g., Osen, 1972; Adams 1979; Cant, 1982; Oliver, 1984a, 1987) and may be monaural (e.g., Semple and Aitkin, 1980). Indirect pathways include a synapse in the superior olivary complex where important binaural cross-correlations are performed (e.g., Boudreau and Tsuchitani, 1968; Goldberg and Brown, 1969). Both the direct and indirect pathways converge in the central nucleus of the inferior colliculus where neurons may display either monaural or binaural responses (Nelson and Erulkar, 1963; Osen, 1972; Roth et al., 1978; Adams, 1979; Semple and Aitkin, 1979; Brunso-Bechtold et al., 1981; Cant, 1982; Kuwada and Yin, 1983a-c; Kuwada et al., 1984; Oliver et al., 1986).

Studies of the inputs and outputs of DNLL show that the DNLL pathway is tonotopically organizcd and parallels the other ascending pathways to the inferior colliculus (Glendenning et al., 1981; Shneiderman et al., 1988). In addition to the inputs from the contralateral side, the DNLL receives inputs from many of the same sources as the inferior colliculus and, thus, has both monaural and binaural inputs. As illustrated in Figure 10 , the main inputs to DNLL are from the ventral cochlear nucleus, LSO, and medial superior olive (MSO). Of these, the primary excitatory inputs are likely to be provided by the contralateral cochlear nucleus, the contralateral LSO, and the ipsilateral MSO. A small projection to the low-frequency DNLL from the ipsilateral cochlear nucleus is probably excitatory. In contrast, the ipsilateral LSO (Hutson et al., 1987; Saint Marie et al., 1987) and the contralateral DNLL may provide inhibitory inputs to DNLL.

The outputs of DNLL (Fig. 10) are to the inferior colliculus on both sides as well as the contralateral DNLL (Goldberg and Moore, 1967; Kudo, 1981; Shneiderman et al., 1988). Projections from DNLL to the contralateral inferior colliculus form bands that parallel the fibrodendritic laminae of the central nucleus (Kudo, 1981; Shneiderman et al., 1988). If the DNLL pathway is inhibitory, it may provide feedforward, inhibitory inputs to the inferior colliculus. Thus, the inhibitory, tonotopically organized bands of the DNLL pathway may complement the other inputs from the direct and indirect pathways (Oliver, 1984a, 1987; Shneiderman and Henkel, 1987; Shneiderman et al., 1988). 


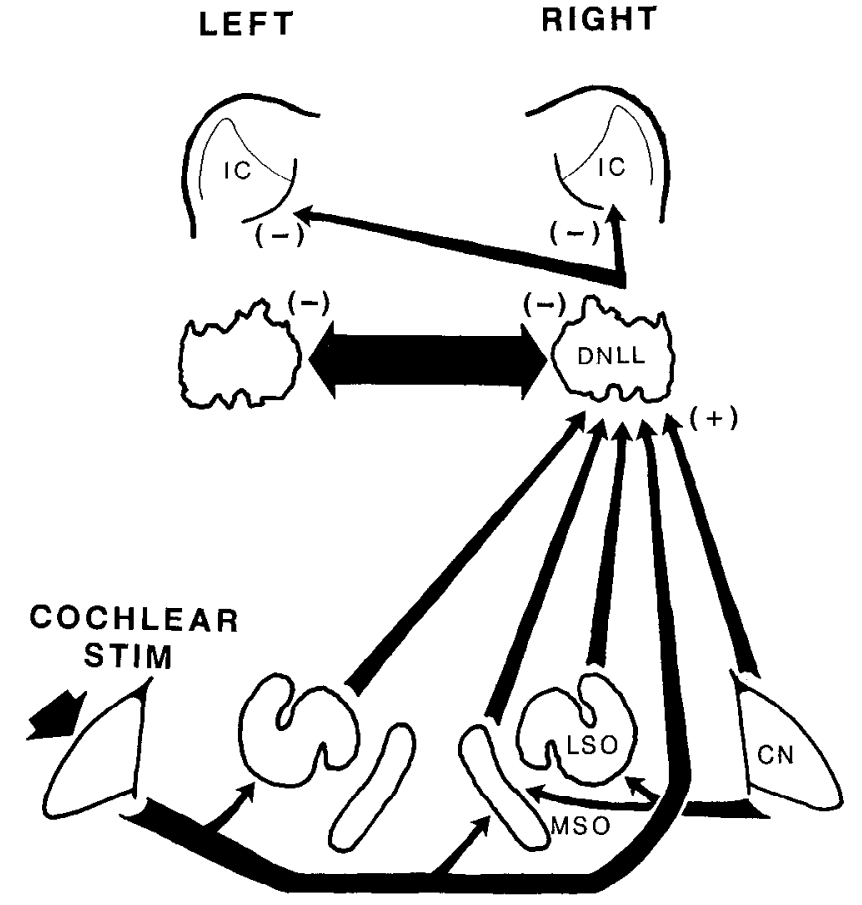

Figure 10. Summary of results. Axonal endings from the contralateral DNLL form numerous synaptic contacts which may effectively inhibit DNLL when active. In contrast, most of the remaining axonal endings in DNLL, unlabeled in this study, are morphologically and functionally different. Ascending pathways may excite DNLL neurons.

\section{Crossed connections between DNLL may regulate the ascending DNLL pathway}

Regulating the flow of ascending inhibitory inputs to the inferior colliculus may be an important function of the reciprocal crossed connection between the 2 DNLL. Since cells in DNLL are binaural (Aitkin et al., 1970; Brugge et al., 1970), they would be influenced by the relative amount of stimulation to one ear versus the other. Shifts from monaural to binaural stimulation might alter the firing rate in the 2 DNLL dramatically. For example, in an experiment using dichotic stimuli delivered through headphones, the primary effect of a monaural stimulus to the left ear (Fig. 10, STIM) could be to activate the contralateral (right) DNLL via the pathways mentioned above. The DNLL pathway through the right side projects bilaterally to the inferior colliculus. Since the right DNLL is excited, the left DNLL would be inhibited via the crossed connections (Fig. 10). This would suppress the ascending inhibitory inputs from the left DNLL pathway. At the same time, inhibition of the left DNLL would disinhibit the right DNLL and possibly augment its response.

In contrast, a free-field stimulus (or a binaural stimulus delivered through headphones) could produce a more complex pattern of activation in one DNLL relative to the other. Depending on the location of the sound in space (or the phase or intensity differences between the ears), the relative amount of activity in the 2 DNLL could vary. For example, a stimulus directly in front (or on the midline with headphones) might result in a symmetrical level of activation in the 2 DNLL, and a balanced level of inhibitory inputs to the infcrior colliculus might result. As a sound moves towards the side (away from the midline), the relative excitation of the 2 DNLL might shift dramatically. Finally, a state similar to a monaural stimulus may be reached as the stimulus is fully lateralized.

Why would an ascending pathway require a mechanism to balance the activity on the 2 sides? Since information in the auditory system reaches the DNLL after the superior olivary complex, DNLL may not be part of the initial mechanism that calculates the location of sound. However, the DNLL pathway could modulate the results of the binaural information transmitted to the inferior colliculus. Such a mechanism could help sharpen the receptive field properties of neurons that respond to the location of a sound in space. If the DNLL pathway is inhibitory, its multisynaptic nature could produce time-delayed IPSPs in the inferior colliculus. Inhibition has become an important part of models to explain interaural time and intensity mechanisms for binaural hearing (Colburn and Moss, 1981; Linderman, 1986). Thus, the study of the DNLL pathway could prove useful in understanding more complex processes in the auditory nervous system.

\section{References}

Adams, J. C. (1979) Ascending projections to the inferior colliculus. J. Comp. Neurol. 183: 519-538.

Adams, J. C. (1981) Heavy metal intensification of DAB-based HRP reaction product. J. Histochem. Cytochem. 29: 775.

Adams, J. C., and E. Mugnaini (1984) Dorsal nucleus of the lateral lemniscus: A nucleus of GABAergic projection neurons. Brain Res. Bull. 13: 585-590.

Aitkin, L. M., D. J. Anderson, and J. F. Brugge (1970) Tonotopic organization and discharge characteristics of single neurons in nucle of the lateral lemniscus of the cat. J. Neurophysiol. 33: 421-440.

Blackett, N. M., and D. M. Parry (1973) $\Lambda$ new method for analyzing electron microscopic autoradiographs using hypothetical grain distributions. J. Cell Biol. 57: 9-15.

Boudreau, J. C., and C. Tsuchitani (1968) Binaural interaction in the cat superior olive S-segment. J. Neurophysiol. 31: 442-454.

Brugge, J. F., D. J. Anderson, and L. M. Aitkin (1970) Responses of neurons in the dorsal nucleus of the lateral lemniscus of cat to binaural tonal stimulation. J. Neurophysiol. 33: 441-458.

Brunso-Bechtold, J. K., G. C. Thompson, and R. B. Masterton (1981) HRP study of the organization of auditory afferents ascending to the central nucleus of inferior colliculus in cat. J. Comp. Neurol. 197 . $705-722$.

Cant, N. B. (1981) The fine structure of two types of stellate cells in the anterior division of the anteroventral cochlear nucleus of the cat. Neuroscience 6: 2643-2655.

Cant, N. B. (1982) Identification of cell types in the anteroventral cochlear nucleus that project to the inferior colliculus. Neurosci. Lett. 32: 241-246.

Cant, N. B. (1984) The fine structure of the lateral superior olivary nucleus of the cat. J. Comp. Neurol. 227: 63-77.

Cant, N. B., and D. K. Morest (1979) The bushy cells in the anteroventral cochlear nucleus of the cat. A study with the electron microscope. Neuroscience 4: 1925-1945.

Colburn, H. S., and P. J. Moss (1981) Binaural interaction models and mechanisms. In Neuronal Mechanisms of Hearing, J. Syka and L. Aitkin, eds., pp. 283-288, Plenum, New York.

Cowan, W. M., D. I. Gottlieb, A. E. Hendrickson, J. L. Price, and T. A. Woolsey (1972) The autoradiographic demonstration of axonal connections in the central nervous system. Brain Res. 37: 21-51.

Edwards, S. B. (1972) The ascending and descending projections of the red nucleus in the cat: An experimental study using an autoradiographic tracing method. Brain Res. 48: 45-63.

Glendenning, K. K., J. K. Brunso-Bechtold, G. C. Thompson, and R. B. Masterton (1981) Ascending auditory afferents to the nuclei of the lateral lemniscus. J. Comp. Neurol. 197: 673-703.

Goldberg, J. M., and P. B. Brown (1969) Response of binaural neurons of dog superior olivary complex to dichotic tonal stimuli: Some physiological mechanisms of sound localization. J. Neurophysiol. 32: 613636.

Goldberg, I. M., and R. Y. Moore (1967) Ascending projections of 
the lateral lemniscus in the cat and monkey. J. Comp. Neurol. 129: $143-156$.

Gray, E. G. (1959) Axo-somatic and axo-dendritic synapses of the cerebral cortex: An electron microscopic study. J. Anat. 93:420-433.

Henkel, C. K., and A. Shneiderman (1988) Efferent connections of nucleus sagulum: A component of the lateral tegmental system in the ascending auditory pathway. Part I-Midbrain connections. J. Comp. Neurol. 221: 416-428.

Hökfelt, T., and A. Ljungdahl (1975) Autoradiographic identification of cerebral and cerebellar cortical neurons accumulating labeled gamma-aminobutyric acid (3H-GABA). Exp. Brain Res. 14: 354-362.

Hutson, K. A., K. K. Glendenning, and R. B. Masterton (1987) Biochemical basis for the acoustic chiasm? Soc. Neurosci. Abstr. 13: 548.

Iwahori, N. (1986) A Golgi study on the dorsal nucleus of the lateral lemniscus in the mouse. Neurosci. Res. 3: 196-212.

Kane, E. C. (1974) Patterns of degeneration in the caudal cochlear nucleus of the cat after cochlear ablation. Anat. Rec. 179: 67-92.

Kane, E. C., and L. M. Barone (1980) The dorsal nucleus of the lateral lemniscus in the cat: Neuronal types and their distributions. J. Comp. Neurol. 192: 797-826.

Kelly, J. S., F. Dick, and F. Schon (1975) The autoradiographic localization of the GABA-releasing nerve terminals in cerebellar glomeruli. Brain Res. 85: 255-259.

Kopf-Maier, P. (1979) A new type of synapse in the ventral cochlear nucleus. Cell Tissue Res. 198: 373-380.

Kopriwa, B. M. (1973) A reliable, standardized method for ultrastructural electron microscopic radioautography. I Iistochemistry 37: 117.

Kudo, M. (1981) Projections of the nuclei of the lateral lemniscus in the cat: An autoradiographic study. Brain Res. 221: 57-69.

Kuwada, S., and T. C. T. Yin (1983a) Binaural interaction in lowfrequency neurons in inferior colliculus of the cat. I. Effects of long interaural delays, intensity, and repetition rate on interaural delay function. J. Neurophysiol. 50: 981-999.

Kuwada, S., and T. C. T. Yin (1983b) Binaural interaction in lowfrequency neurons in inferior colliculus of the cat. II. Effects of changing rate and direction of interaural phase. J. Neurophysiol. 50: 10001019.

Kuwada, S., and T. C. T. Yin (1983c) Binaural interaction in lowfrequency neurons in inferior colliculus of the cat. III. Effects of changing frequency. J. Neurophysiol. 50: 1020-1041.

Kuwada, S., T. C. T. Yin, J. Syka, T. J. F. Buunen, and R. E. Wickesberg (1984) Binaural interaction in low-frequency neurons in inferior colliculus of the cat. IV. Comparison of monaural and binaural response properties. J. Neurophysiol. 51: 1306-1325.

Lenn, N. J., and T. S. Reese (1966) The fine structure of nerve endings in the nucleus of the trapezoid body and the ventral cochlear nucleus. Am. J. Anat. 118: 375-389.

Linderman, W. (1986) Extension of a binaural cross-correlation model by contralateral inhibition. I. Stimulation of lateralization for stationary signals. J. Acoust. Soc. Am. 80: 1608-1622.

Lund, R. D., and L. E. Westrum (1966) Synaptic vesicle differences after primary formalin fixation. J. Physiol. (Lond.) 185: 7P-9P.

McLaughlin, B. J., J. G. Wood, K. Saito, E. Roberts, and J.-Y. Wu (1974) The fine structural localization of glutamate decarboxylase in synaptic terminals of rodent cerebellum. Brain Res. 76: 377-391.

Mesulam, M. M. (1978) Tetramethyl benzidine for horseradish peroxidase neurohistochemistry: A non-carcinogenic blue reaction-product with superior sensitivity for visualizing neuronal afferents and efferents. J. Histochem. Cytochem. 26: 106-177.

Moore, J. K., and R. Y. Moore (1987) Glutamic acid decarboxylaselike immunoreactivity in brainstem auditory nuclei of the rat. J. Comp. Neurol. 260: 157-174.

Moore, M. J., and D. M. Caspary (1983) Strychnine blocks binaural inhibition in lateral superior olivary neurons. J. Neurosci. 3: 237242.

Morest, D. K. (1975) Synaptic relationships of Golgi type II cells in the medial geniculate body of the cat. J. Comp. Neurol. 162: 157194.

Nelson, P. G., and S. D. Erulkar (1963) Synaptic mechanisms of excitation and inhibition in the central auditory pathway. J. Neurophysiol. 26: 908-923.

Oliver, D. L. (1984a) Dorsal cochlear nucleus projections to the inferior colliculus in the cat: A light and electron microscopic study. J. Comp. Neurol. 224: 155-172.

Oliver, D. L. (1984b) Neuron types in the central nucleus of the inferior colliculus that project to the medial geniculate body. Neuroscience 11: 409-424.

Oliver, D. L. (1985) Quantitative analyses of axonal endings in the central nucleus of the inferior colliculus and distribution of $3 \mathrm{H}$-labeling after injections in the dorsal cochlear nucleus. J. Comp. Neurol. 237: 343-359.

Oliver, D. L. (1987) Projections to the inferior colliculus from the anteroventral cochlear nucleus in the cat: Possible substrates for binaural interaction. J. Comp. Neurol. 264: 24-46.

Oliver, D. L., and W. C. Hall (1978) The medial geniculate body of the tree shrew, Tupaia glis. I. Cytoarchitecture and midbrain connections. J. Comp. Neurol. 182: 423-458.

Oliver, D. L., S. J. Potashner, D. R. Jones, and D. K. Morest (1983) Selective labeling of spiral ganglion and granule cells with $\mathrm{D}$-aspartate in the auditory system of cat and guinea pig. J. Neurosci. 3: 455-472.

Oliver, D.L., S. Kuwada, R. Batra, T. R. Stanford, and C. Henkel (1986) Structural components of binaural information processing in the auditory midbrain. Physiology and anatomy of HRP-injected cells in the cat and gerbil. Soc. Neurosci. Abstr. 12: 1271.

Oliver, D. L., A. Schneiderman [sic], and C. K. Henkel (1987a) Morphological substrates for binaural interaction in the midbrain: The dorsal nucleus of the lateral lemniscus. Assoc. Res. Otolarnygol. Abstr. Midwinter Meeting 10: 218.

Oliver, D. L., A. Shneiderman, and C. Henkel (1987b) Morphological substrates for binaural interaction in the midbrain: Afferents to the dorsal nucleus of the lateral lemniscus. Soc. Neurosci. Abstr. 13: 547.

Osen, K. K. (1972) Projection of the cochlear nuclei on the inferior colliculus in the cat. J. Comp. Neurol. 144: 355-372.

Parry, D. M. (1976) Practical approaches to the statistical analysis of electron microscopic autoradiograms. J. Microsc. Biol. Cell. 27: 185189.

Potashner, S. J. (1983) Uptake and release of D-aspartate in the guinea pig cochlear nucleus. J. Neurochem. 41: 1094-1101.

Probst, M. (1902) Experimentelle untersuchungen uber die anatomie und physiologie der leitungsbahnen des gehirnstammes. Arch. Anat. Physiol. (Suppl.) 47: 254.

Ribak, C. E. (1978) Aspinous and sparsely-spinous stellate neurons in the visual cortex of rats contain glutamic acid decarboxylase. $J$. Neurocytol. 7: 461-478.

Ribak, C. E., J. E. Vaughn, K. Saito, R. Barber, and E. Roberts (1977) Glutamate decarboxylase localization in neurons of the olfactory bulb. Brain Res. 126: 1-18.

Roberts, R. C., and C. E. Ribak (1987) GABAergic neurons and axon terminal in the brainstem auditory nuclei of the gerbil. J. Comp. Neurol. 258: 267-280.

Roth, G. L., L. M. Aitkin, R. A. Andersen, and M. M. Merzenich (1978) Some features of the spatial organization of the central nucleus of the inferior colliculus of the cat. J. Comp. Neurol. 182: 661-680.

Saint Marie, R. L., E.-M. Ostapoff, D. K. Morest, and R. J. Wenthold (1987) The chemical acoustic chiasm: Asymmetric glycine immunoreactivity in the bilateral projection from the lateral superior olive to the inferior colliculus in the cat. Soc. Neurosci. Abstr. 13:548.

Salpeter, M. M., H. C. Ferteck, and E. E. Salpeter (1977) Resolution in electron microscopic autoradiography. III. Iodine-125, the effect of heavy metal staining, and a reassessment of critical parameters. J. Cell Biol. 72: 161-173.

Salpeter, M. M., F. A. McHenry, and E. E. Salpeter (1978) Resolution in electron microscopic autoradiography. IV. Application to analysis of autoradiographs. J. Cell Biol. 76: 127-145.

Semple, M. N., and L. M. Aitkin (1979) Representation of sound frequency and laterality by units in central nucleus of cat inferior colliculus. J. Neurophysiol. 42: 1626-1639.

Semple, M. N., and L. M. Aitkin (1980) Physiology of pathway from dorsal cochlear nucleus to inferior colliculus revealed by electrical and auditory stimulation. Exp. Brain Res. 41: 19-28.

Shneiderman, A., and C. K. Henkel (1987) Banding of lateral superior olivary nucleus afferents in the inferior colliculus: A possible substrate for sensory integration. J. Comp. Neurol. 266: 519-534.

Shneiderman, A., and D. L. Oliver (1988) Reciprocal inhibitory connection in the auditory system. An electron microscopic study of the dorsal nuclei of the lateral lemniscus. Anat. Rec. 220: 89A.

Shneiderman, A., D. L. Oliver, and C. K. Henkel (1988) The connections of the dorsal nucleus of the lateral lemniscus. An inhibitory parallel pathway in the ascending auditory system? J. Comp. Neurol. 276: 188-208.

Smith, P. H., and W. S. Rhode (1985) Electron microscopic features 
of physiologically characterized, HRP-labeled fusiform cells in the cat dorsal cochlear nucleus. J. Comp. Neurol. 237: 127-143.

Tanaka, K., K. Otani, A. Tokunaga, and S. Sugita (1985) The organization of neurons in the nucleus of the lateral lemniscus projecting to the superior colliculi in the rat. Brain Res. 341: 252-260.

Thompson, G. C., A. M. Cortez, and D. M. Lam (1985) Localization of GABA immunoreactivity in the auditory brainstem of guinea pigs. Brain Res. 339: 119-122.

Tolbert, L. P., and D. K. Morest (1982) The neuronal architecture of the anteroventral cochlear nucleus of the cat in the region of the cochlear nerve root: Electron microscopy. Neuroscience 7: 30533067.

Uchizono, K. (1965) Characteristics of excitatory and inhibitory synapses in the central nervous system of the cat. Nature 207: 642-643. Valdivia, O. (1971) Methods of fixation and the morphology of synaptic vesicles. J. Comp. Neurol. 142: 257-274. van Noort, J. (1969) The Structure and Connections of the Inferior Colliculus. An Investigation of the Lower Auditory System, Assen, Van Gorcum.

Vaughn, J. E., E. V. Famigilietti, Jr., R. P. Barber, K. Saito, E. Roberts, and C. E. Ribak (1981) GABAergic amacrine cells in rat retina: Immunocytochemical identification and synaptic connectivity. $J$. Comp. Neurol. 197: 113-127.

Wallberg, F. (1966) Elongated vesicles in terminal boutons of the central nervous system, a result of aldehyde fixation. Acta Anat. 65: 224-235.

Wenthold, R. J., and R. F. Gulley (1977) Aspartic acid and glutamic acid levels in the cochlear nucleus after auditory nerve lesion. Brain Res. 138: 111-123.

Wenthold, R. J., J. M. Zempel, M. H. Parakkal, K. A. Reeks, and R. A. Altschuler (1986) Immunocytochemical localization of GABA in the cochlear nucleus of the guinea pig. Brain Res. 380: 7-18. 